\title{
Anesthetic management for
}

Korean Journal of Anesthesiology separation of thoracopagus twins with complex congenital heart

\section{disease}

\section{-a case report-}

\author{
Misook Seo ${ }^{1}$, In-Sun Chung ${ }^{2}$, Myong-Hwan $\mathrm{Karm}^{1}$, Ji Mi Oh${ }^{1}$, and \\ Won-Jung Shin ${ }^{1}$ \\ Department of Anesthesiology and Pain Medicine, ${ }^{1}$ Asan Medical Center, University of Ulsan College of Medicine, \\ ${ }^{2}$ Samsung Medical Center, Sungkyunkwan University School of Medicine, Seoul, Korea
}

\begin{abstract}
Although thoracopagus twins joined at the upper chest are the most common type of conjoined twins, the separation surgery in these cases has a higher mortality rate. Here, we describe an anesthetic management approach for the separation of thoracopagus conjoined twins sharing parts of a congenitally defective heart and liver. We emphasize the importance of vigilant intraoperative hemodynamic monitoring for early detection of unexpected events. Specifically, real-time continuous monitoring of cerebral oximetry using near-infrared spectroscopy allowed us to promptly detect cardiac arrest and hemodynamic deterioration.
\end{abstract}

Key Words: Conjoined twins, Thoracopagus twins.

Thoracopagus twins joined at the upper chest are the most common type of conjoined twins. Despite advances in prenatal diagnosis and surgery, the anesthesia for separation remains demanding, complicated, and unestablished. Particularly for conjoined twins sharing a common heart, the survival rate after

Corresponding author: Won-Jung Shin, M.D., Ph.D.

Department of Anesthesiology and Pain Medicine, Laboratory for Cardiovascular Dynamics, Asan Medical Center, University of Ulsan College of Medicine, 88, Olympic-ro 43-gil, Songpa-gu, Seoul 138-736, Korea

Tel: 82-2-3010-3868, Fax: 82-2-3010-6790

E-mail: wjshin@amc.seoul.kr

Received: May 14, 2014.

Revised: August 20, 2014.

Accepted: August 28, 2014.

Korean J Anesthesiol 2015 June 68(3): 295-299

http://dx.doi.org/10.4097/kjae.2015.68.3.295 separation surgery is extremely low $[1,2]$. Here, we describe an anesthetic management approach for the separation of thoracopagus conjoined twins sharing a congenitally defective heart and liver. We emphasize the importance of intraoperative monitoring to detect the hemodynamic deterioration associated with cardiac dysfunction and massive bleeding during separation surgery.

\section{Case Report}

Thoracopagus conjoined twins were born at 38 weeks gestational age by cesarean section, with a combined birth weight of $4.16 \mathrm{~kg}$. Preoperative cardiac computed tomography showed that Twin A (the right-sided baby) had levocardia with supracardiac total anomalous pulmonary venous return (TAPVR), persistent ductusarteriosus, and congenitally corrected transposition of the great arteries with an atrial septal defect, while Twin B (the left-sided baby) demonstrated mesocardia, a right aortic arch,

(c) This is an open-access article distributed under the terms of the Creative Commons Attribution Non-Commercial License (http://creativecommons.org/ licenses/by-nc/4.0/), which permits unrestricted non-commercial use, distribution, and reproduction in any medium, provided the original work is properly cited. 
absence of the right superior vena cava (SVC), and supracardiac TAPVR. In addition, there was extensive atrial communication between the twins, and we could not rule out a ventricular myocardial connection. Abdominal computed tomography revealed fused hepatic tissues with separated hepatobiliary tracts and bowel loops. Three days after birth, Twin A developed oliguria with azotemia, whereas Twin B required mechanical ventilation with endotracheal intubation. We decided to separate the twins at 8 days after birth to prevent advanced heart failure and multiorgan dysfunction.

All anesthetic and monitoring equipment were duplicated, and intravenous accesses and drugs were color labeled (i.e., Twin A, pink; Twin B, blue) for easy identification. The twins were positioned so that the left side of Twin A was facing down. Each twin underwent routine monitoring, including electrocardiography (ECG) and noninvasive blood pressure, pulse oximetry, and end-tidal $\mathrm{CO}_{2}$ assessment. When the twins arrived in the operating room, the initial vital signs of Twin A were 120/78 $\mathrm{mmHg}$ blood pressure with continuous dopamine $5 \mu \mathrm{g} / \mathrm{kg} / \mathrm{min}$ and dobutamine $5 \mu \mathrm{g} / \mathrm{kg} / \mathrm{min}$, 95\% peripheral oxygen saturation $\left(\mathrm{SpO}_{2}\right)$, and $163 / \mathrm{min}$ heart rate; Twin $\mathrm{B}$ had already been intubated, with $86 / 42 \mathrm{mmHg}$ blood pressure, $94 \% \mathrm{SpO}_{2}$, and $165 / \mathrm{min}$ heart rate. We also monitored invasive arterial blood pressure at the left dorsalispedis artery in Twin A due to failure at the radial and femoral arteries and at the right radial artery in Twin B. Synchronized cardiac rhythms and pulse waves were noted in the twins (Fig. 1A). Twin B was inclined by approximately $15^{\circ}$ using a support pad. We then ensured the possibility of mask ventilation in Twin $\mathrm{A}$ in the supine position because Twin B was already intubated.

We performed anesthetic induction of Twin A intravenously with $30 \mu \mathrm{g}$ atropine, $0.3 \mathrm{mg}$ midazolam, $10 \mu \mathrm{g}$ fentanyl, and 0.2 $\mathrm{mg}$ vecuronium. Immediately after administration of anesthetics to Twin A, Twin B also became sedated and relaxed. Twin A was successfully intubated with a $3.5 \mathrm{~mm}$ cuffed endotracheal tube. Because the SVC of Twin A was on the right, while that of Twin $B$ was on the left, we decided to insert double-lumen 4 Fr central venous catheters (Arrow International Inc., Reading, PA, USA) under ultrasound guidance in each twin's internal jugular vein. When the guide wire was advanced for central venous catheterization in Twin A, sudden ventricular tachyarrhythmia and hypotension occurred. At that moment, ECG and arterial blood pressure monitoring of Twin B showed ventricular tachyarrhythmia (Fig. 1B). However, in less than a minute, the tachyarrhythmia spontaneously reverted to normal rhythm without any specific treatment. A central venous catheter was then placed uneventfully in Twin B. We secured additional intravenous lines via the left femoral venous catheter in Twin A and the left external jugular venous catheter in Twin B to facilitate rapid administration of fluids and blood products. In addition, a pediatric-sized oxim- etry sensor was placed on the forehead of each twin to assess cerebral regional oxygen saturation $\left(\mathrm{rSO}_{2}\right)$ using near-infrared spectroscopy (INVOS 5100; Somanetics, Troy, MI, USA). The ini-
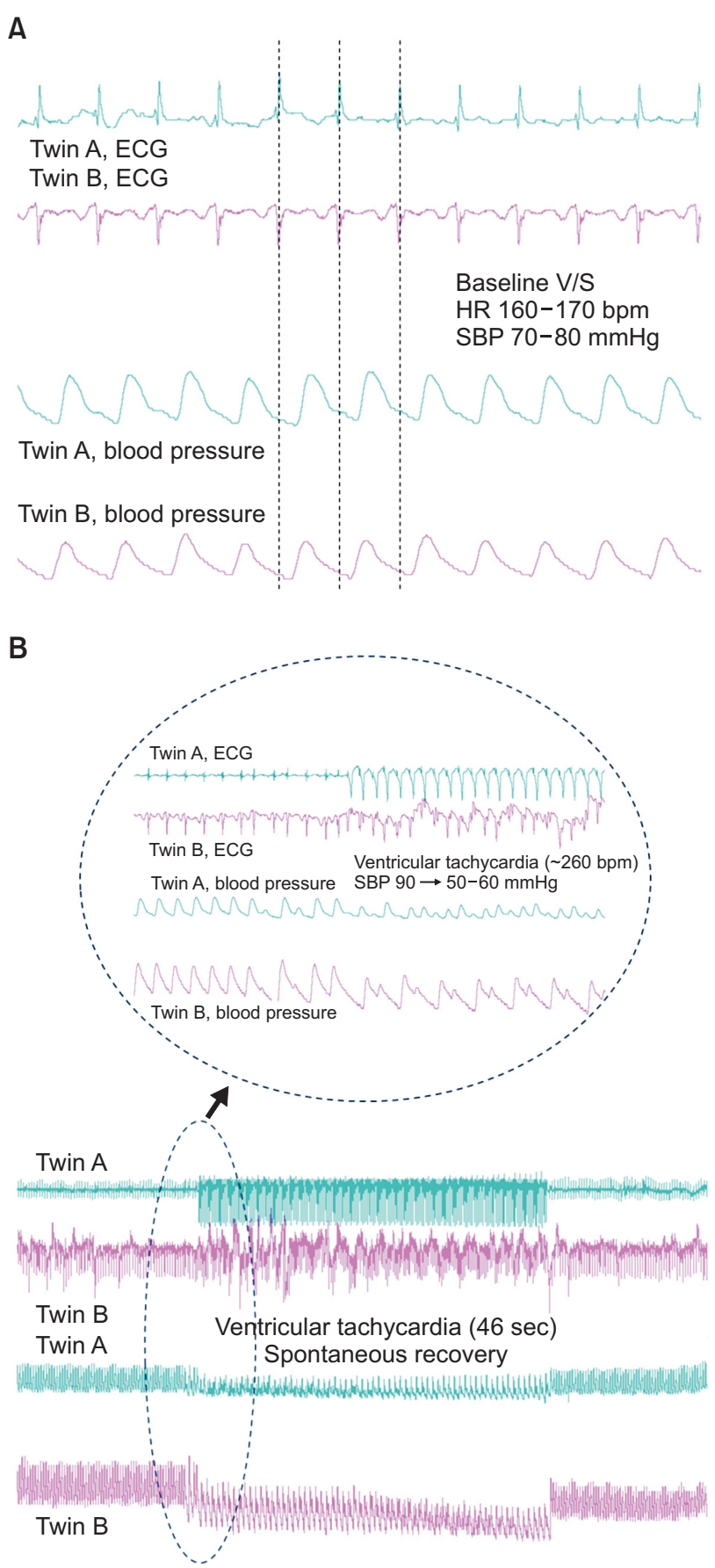

Fig. 1. Intraoperative electrocardiography (ECG) and arterial blood pressure waveforms displayed on the same screen. (A) The baseline ECG of the twins showed synchronized cardiac rhythms. (B) Ventricular tachyarrhythmia occurred simultaneously in both twins during central catheterization of Twin A. Tachyarrhythmia and hypotension terminated without specific treatments. 
tial cerebral $\mathrm{rSO}_{2}$ of Twin A and Twin B was 62 and 53\%, respectively. All data from ECG, arterial blood pressure, and central venous pressure waveforms of both twins were simultaneously displayed on the same screen and recorded using an analogueto-digital converter (DI-149; DATAQ Instruments, Akron, $\mathrm{OH}$, USA). Cerebral $\mathrm{rSO}_{2}$ values were also automatically saved to a USB device every 5-6 seconds throughout the operation.

Surgery was commenced with a median sternotomy by a pediatric cardiac surgeon, and dissection revealed extensive atrial communication with separated ventricular myocardial structures. Under cardiopulmonary bypass (CPB) of Twin A accompanied by induced ventricular fibrillation, the atrial communication was clamped and divided. After complete separation of the fused cardiac tissue, the coronary sinus, mitral annulus, and coronary branches of Twin A were damaged, resulting in reduced cardiac contractility with complete atrioventricular block. Twin A required inotropic support and temporary cardiac pacing (VVI mode, 150 beats/min) for weaning from $\mathrm{CPB}$. When $\mathrm{CPB}$ was stopped, the blood pressure of Twin A was 85/60 with continuous dopamine $10 \mu \mathrm{g} / \mathrm{kg} / \mathrm{min}$ and epinephrine $0.05 \mu \mathrm{g} / \mathrm{kg} / \mathrm{min}$. In contrast, Twin B showed increased arterial blood pressure and good cardiac contractility after separation. Following weaning from CPB, Twin A showed a decrease in cerebral $\mathrm{rSO}_{2}$ below $35 \%$ (Fig. 2) and blood pressure was 75/55 mmHg. Heparin was reversed by injecting each twin with protamine $6 \mathrm{mg}$.

Next, separation of the shared liver was started. Because the hepatic vessels could not be clearly distinguished from each other, there was massive bleeding, as expected. Nevertheless, our team believed that Twin A would be worse due to his damaged heart, which would influence Twin B's prognosis if separation was stopped. At first, we administered packed red blood cells (PRBCs), Plasma-Lyte solution, and 5\% albumin. After

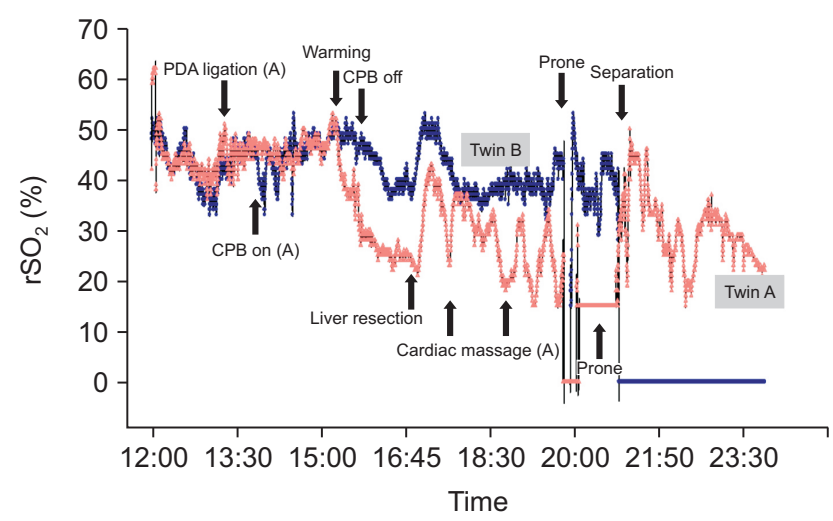

Fig. 2. Cerebral oxygen saturation $\left(\mathrm{rSO}_{2}\right)$ monitoring during separation surgery of thoracopagus conjoined twins. After separation of the fused atria, the cerebral $\mathrm{rSO}_{2}$ of Twin A (light pink) decreased concomitantly with cardiac arrest and position change. Twin A showed a poorer outcome than Twin B (dark blue), who had a well-maintained cerebral $\mathrm{rSO}_{2}$. PDA: persistent ductusarteriosus, $\mathrm{CPB}$ : cardiopulmonary bypass. replacement of 1.0 blood volume loss with PRBC, fresh frozen plasma (FFP) was administered. Blood products were delivered at a PRBC : FFP volume ratio of $2: 1$ [3]. The estimated blood loss until the end of separation was approximately $730 \mathrm{ml}$. The total amount of infused blood of Twin A was as follows: $220 \mathrm{ml}$ filtered RBCs, $130 \mathrm{ml}$ FFPs, $90 \mathrm{ml}$ platelets, and $30 \mathrm{ml}$ cryoprecipitates. The total amount of infused bloodfor Twin B was: 410 ml filtered RBCs, $190 \mathrm{ml}$ FFPs, 150 mlplatelets, and $30 \mathrm{ml}$ cryoprecipitates. Fortunately, the vital signs did not change acutely for either twin.

Immediately after complete separation of the liver, cardiac arrest occurred in Twin A. Cardiac massage was performed and epinephrine was given. Although a heartbeat was restored, arterial blood pressure was not consistently detectable. Dampened arterial blood pressure waveforms were inappropriate for hemodynamic monitoring, and we therefore managed Twin A with vasoactive inotropic agent (dopamine $10 \mu \mathrm{g} / \mathrm{kg} / \mathrm{min}$, epinephrine $0.05 \mu \mathrm{g} / \mathrm{kg} / \mathrm{min}$, and milrinone $0.375 \mu \mathrm{g} / \mathrm{kg} / \mathrm{min}$ ) and fluids based on his cerebral $\mathrm{rSO}_{2}$ values (Fig. 2) and noninvasive blood pressure. We then reversed the babies horizontally by $180^{\circ}$ degrees to divide the remaining conjoined tissues, but Twin A again developed circulatory collapse due to compression of the protruding heart. We injected Twin A 4 times with epinephrine $2 \mu \mathrm{g}$ during the remaining separation.

After complete separation of the bodies of the twins, an aortic pressure line was inserted in Twin A's heart, and the blood pressure at that time was $45 / 27 \mathrm{mmHg}$. Twin B was transferred to another operating room for the remaining procedures. The large skin defects of the twins were covered with porcine dermal implant (Permacol ${ }^{\mathrm{TM}}$; Tissue Science Laboratory, Covington, GA, USA) and silastic membranes, and the twins were transferred to the intensive care unit for postoperative care. Two hours after surgery, cardiac arrest repeatedly occurred in Twin A. Cardiopulmonary resuscitation was performed, but the survival of Twin A was deemed unlikely. We then planned to donate the skin of Twin A to Twin B to cover the defects of Twin B's wound. Twenty-eight days after separation, Twin B underwent cardiac surgery including TAPVR repair and ventricular septal defect closure. However, 84 days after separation, Twin B died of refractory septic shock.

\section{Discussion}

Reports on the successful separation of fused hearts in conjoined twins are rare [2,4]. The overall mortality rate for thoracopagus twins who have significant cardiac fusion is close to $100 \%[5,6]$. TAPVR is present in more than one-third of conjoined twins, resulting in adverse surgical outcomes [5]. In addition, it is very difficult to accurately evaluate the complexity of the conjunction between twins and to predict which twin 
is most likely to survive after separation. In the present report, we present certain challenges in anesthetic management during separation of thoracopagus twins with a fused heart and liver.

The twins in our current case had complex congenital heart disease requiring emergency surgery and a low weight of $2 \mathrm{~kg}$ each. They therefore incurred a risk of limited vascular access for hemodynamic monitoring and fluid administration. Furthermore, it is difficult to reposition conjoined twins that lie face-to-face in order to expose the normal anatomic regions for arterial and venous access. In addition, lines for fluid administration and monitoring should be kept away from the surgical field and secured carefully [7,8]. Considering the limitations of hemodynamic monitoring, we chose cerebral $\mathrm{rSO}_{2}$ monitoring using near-infrared spectroscopy, which provides information on systemic perfusion and oxygen balance [9-11]. After CPB, Twin A needed continuous epinephrine support to maintain blood pressure and his $\mathrm{rSO}_{2}$ decreased acutely. We assumed that the decreased cardiac function of Twin A was related to his decreased $\mathrm{rSO}_{2}$. Non-functioning of the arterial line after liver resection complicated the management of Twin A and we contend that $\mathrm{rSO}_{2}$ values and noninvasive blood pressure should be used in such a situation.

Our present study also highlights the risk of complications associated with the synchronized cardiac rhythm of conjoined twins. Ventricular or atrial electromyocardial continuities between conjoined twins have been reported to result in synchronous heart beats $[12,13]$. Recently, it was reported that conjoined twins with a single QRS on ECG have unfavorable outcomes [6]. The simultaneous development of tachyarrhythmia during central catheterization suggests that in this case the sinus node of one of the twins paced both hearts through electrophysiological continuity. After separation of the conjunction between the crux of Twin A and coronary sinus of Twin B, the cardiac rhythm of Twin A suggested complete heart block requiring pericardial pacing, whereas the ECG of Twin B indicated normal sinus rhythm. Thus, separation compromised the cardiac conduction and myocardial function of Twin A. Throughout surgery, we monitored and recorded the ECG and arterial waveforms of both twins on the same screen. This method of ECG monitoring is important for proper management, although we could not predict the heart block or tachyarrhythmia as electrophysiological consequences of cardiac tissue separation.

It is important to consider that external cardiac massage can be unreliable and has limited efficacy, particularly for the fused hearts of conjoined twins. In our present case, it was possible to perform internal cardiac massage because the cardiac arrest in Twin A occurred after the heart was exposed and separated. Therefore, it is important to bear in mind that prompt correction of hemodynamic instability and prevention of cardiac arrest is crucial. In this respect, vigilant monitoring of real-time ECG, arterial blood pressure, and $\mathrm{rSO}_{2}$ is vital.

In cases of complex heart or liver conjunction, blood loss can be anticipated to exceed 3-4 times the estimated blood volume of each twin [7]. Sudden massive bleeding and transfusion is not well tolerated by twins with congenital heart disease. In the case of massive PRBC transfusion, a PRBC : FFP ratio of $2: 1$ is recommended. Platelet replacement is dependent on the initial platelet count and lost blood volume: if the platelet count decreases below $50,000 / \mathrm{mm}^{3}$, replacement with 10 to $15 \mathrm{ml} / \mathrm{kg}$ platelets should be started. Additional cryoprecipitate ( 0.2 to 0.4 units/ $\mathrm{kg}$ ) is required in the presence of consumption coagulopathy [3]. To avoid complications associated with massive transfusion, we administered blood products in accordance with the above protocol. We also used freshly drawn blood products with a low concentration of plasma potassium and free hemoglobin [14]. In our center, we usually infuse fresh blood products (drawn within 3 days previously) in high-risk patients such as these twins. In addition, cryoprecipitates and calcium infusion were delivered appropriately, and body temperature was maintained at $35.0-35.5^{\circ} \mathrm{C}$ with blanketrol, warm air convection, and a venous fluid line warmer. Because of this planned protocol, significant complications such as pulmonary edema, hyperkalemia, and dilutional coagulopathy were averted. Point-of-care hemostatic assays, thromboelastography, and rotational thromboelastometry are also helpful for assessing hemostatic disturbances during massive transfusion [15]. However, these methodologies were unavailable in our current case. Most importantly, packages of blood products should be prepared for an immediate response when a massive transfusion protocol is triggered.

Although our current case of separation surgery of thoracopagus twins with synchronous cardiac rhythms and congenital heart diseases had a poor clinical outcome, we still emphasize the importance of intraoperative vigilant hemodynamic monitoring for early detection of unexpected events. When there is an absence of compulsory monitors, such as in the present case due to non-functioning of the arterial line, real-time $\mathrm{rSO}_{2}$ monitoring can also aid patient management, even though our results were not good. On the basis of meticulous monitoring, we predict that multidisciplinary approaches can improve the survival outcomes for high-risk conjoined twins. 


\section{References}

1. O’Neill JA Jr, Holcomb GW 3rd, Schnaufer L, Templeton JM Jr, Bishop HC, Ross AJ 3rd, et al. Surgical experience with thirteen conjoined twins. Ann Surg 1988; 208: 299-312.

2. Suan C, Ojeda R, Garcia-Perla JL, Cerro J, Romero D, Gilabert J, et al. Anaesthetic management of the surgical separation of a pair of thoracopagus-cardiopagus twins. Paediatr Anaesth 1998; 8: 255-7.

3. Cote CJ, Lerman J, Anderson BJ. A Practice of Anesthesia for Infants and Children. 5th ed. Philadelphia, Elsevier. 2013, pp 205-11.

4. Brown DL, Holubec DM, Towle DJ, Bodary AK, Patterson AR, Mack J. Anesthetic management of thoracopagus twins undergoing cardiopagus separation. Anesthesiology 1985; 62: 679-82.

5. Thomas Collins R 2nd, Weinberg PM, Gruber PJ, St John Sutton MG. Conjoined hearts in thoracopagus twins. Pediatr Cardiol 2012; 33: 252-7.

6. McMahon CJ, Spencer R. Congenital heart defects in conjoined twins: outcome after surgical separation of thoracopagus. Pediatr Cardiol 2006; 27: 1-12.

7. Thomas JM. Anaesthesia for conjoined twins. Childs Nerv Syst 2004; 20: 538-46.

8. Thomas JM, Lopez JT. Conjoined twins--the anaesthetic management of 15 sets from 1991-2002. Paediatr Anaesth 2004; 14: 117-29.

9. Ghanayem NS, Wernovsky G, Hoffman GM. Near-infrared spectroscopy as a hemodynamic monitor in critical illness. Pediatr Crit Care Med 2011; 12 (4 Suppl): S27-32.

10. Mittnacht AJ. Near infrared spectroscopy in children at high risk of low perfusion. Curr Opin Anaesthesiol 2010; $23: 342-7$.

11. Zulueta JL, Vida VL, Perisinotto E, Pittarello D, Stellin G. Role of intraoperative regional oxygen saturation using near infrared spectroscopy in the prediction of low output syndrome after pediatric heart surgery. J Card Surg 2013; 28: 446-52.

12. Benjamin LC, Nahar J, Sable C, Midgley FM, Di Russo GB. Separation of thoracopagus-cardiopagus twins joined by a myocardial bridge. J Thorac Cardiovasc Surg 2005; 130: 1212-3.

13. Wu MH, Lai YC, Lo HM, Hsu YH, Lue HC. Assessment of electromyocardial continuity in conjoined (thoracopagus) twins. Am J Cardiol 1992; 69: 830-2.

14. Lee AC, Reduque LL, Luban NL, Ness PM, Anton B, Heitmiller ES. Transfusion-associated hyperkalemic cardiac arrest in pediatric patients receiving massive transfusion. Transfusion 2014; 54: 244-54.

15. Diab YA, Wong EC, Luban NL. Massive transfusion in children and neonates. Br J Haematol 2013; 161: 15-26. 